\title{
Predictors of Physician Comfort in Using Pharmacogenomics Data in Clinical Practice: A cross-sectional Study
}

\author{
Prince Otchere ${ }^{1}$, Stella Pak ${ }^{2}$, Edinen Asuka ${ }^{3}$
}

${ }^{1}$ Department of Cardiovascular, Kettering Medical Center, Kettering, 45429, Ohio, ${ }^{2}$ Department of Medicine, Orange Regional Medical Center, New York, 10940, United States, ${ }^{3}$ All Saints University School, of Medicine, Dominica, Caribbean

Address for correspondence: Stella Pak, Department of Medicine, Orange Regional Medical Center, 707 East Main Street, Middletown, New York 10940, United States. Phone: 845-333-1000.

Email: stella.pak@rockets.utoledo.edu

\section{Abstract}

Objective: Utilization of pharmacogenomics data in clinical practice is a critical step toward individual and precision medicine. This is a cross-sectional study conducted by incorporating several variables as outlined in the survey report to assess and analyze the reasons or behaviors that could influence clinicians to use or not use pharmacogenomics. Materials and Methods: In this study, we conducted a cross-sectional quantitative survey among primary physicians practicing in Kettering Health Network facilities. 1201 invitations were sent out and 135 physicians participated in the survey. Physicians were requested by email to participate in a survey containing 14 multiple choice questions regarding their understanding and beliefs regarding pharmacogenomics, as well as questions about specific professional details which were intended to explore how physician characteristics affected familiarity, and comfort and confidence in using pharmacogenomics data inpatient care. Statistical Package for the Social Sciences (standard version 25) was used for statistical analysis, and consent was obtained from all study participants through the survey link. Results: The ratings of the familiarly, comfort, and confidence with pharmacogenetics were highly intercorrelated ( $r=0.81-0.87$ ). Accordingly, we summed the three ratings to form a composite score of the three items; hereafter referred to as "scale scores." Possible scores ranged from 5 to 15 , whereas actual scores ranged from 3 to 15 (Mean $=6.32, \mathrm{SD}=3.12$ ). Scale scores were not statistically significantly correlated with age $(r=0.12, P<0.17)$ or number of years in practice $(r=0.11, P<0.22)$, and were only weakly (inversely) correlated with number of hours spent in patient care each week $(r=-0.17, P<0.05)$. Conclusion: In our study, physicians who had some education in the field of pharmacogenomics were more likely to use pharmacogenomics data in clinical practice. We have further characterized that continuing medical education (CME), more than medical education or residency training significantly predicts familiarity, confidence or comfort in using pharmacogenomics data. Therefore, pharmacogenomics should be integrated in the CME for practicing clinicians as well as graduate medical education.

Keywords: Clinical practice, Continuing medical education, Cross-sectional study, Graduate medical education, Pharmacogenomics data, Pharmacogenomics testing, Pharmacogenomics, Precision medicine

\section{Introduction}

Pharmacogenomicsisthestudyofhowinterindividual variability in genes affects drug response. ${ }^{[1,2]}$ It has also been found that greater than half of drugs with known drug adverse reaction are metabolized by polymorphic enzymes. ${ }^{[3]}$ Furthermore, adverse drug reactions have been found to be the fifth leading cause of death in the United States. ${ }^{[4]}$

The utility of pharmacogenomics is essential to tailor treatment on the basis of genetic profile. By

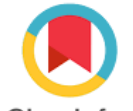

Check for updates

How to cite this article: Otchere P, Pak S, Asuka E. Predictors of Physician Comfort in using Pharmacogenomics Data in Clinical Practice: A cross-sectional Study. $J$ Med Res Innov. 2020;4(2):e000221.

DOI: $10.32892 /$ jmri.221

Publication history: Received: 05-05-2020 Accepted: 28-05-2020 Published: 31-05-2020

Editor: Dr. Varshil Mehta

Copyright: Otchere $\mathrm{P}$, Pak S, Asuka E. This is an open-access article distributed under the terms of the Creative Commons Attribution License CCBY 4.0., which permits unrestricted use, distribution, and reproduction in any medium, provided the original author and sources are credited.

Funding: NIL.

Conflict of Interest: NIL

MK Medkrux 


\section{Otchere, et al.: Use of pharmacogenomics data in clinical practice}

understanding the genetic profiles of individual patients, we could also have a greater understanding of responsiveness to a given drug before starting it. Since pharmacogenomics has become an integral part of precision medicine, the potential impacts include decreasing morbidity and mortality as well as promoting cost effectiveness.

Since the conception of pharmacogenomics, it has become more apparent genetics contributed to the varying drug responses in several ways. ${ }^{[5]}$ To this day, genomic information is continuously being generated in laboratories and integrated into electronic medical records. Automatic computerbased alerts that "fire" is a method to help consider a pharmacogenomics test when a drug is prescribed. ${ }^{1,5]}$ One study known as the "RIGHT" protocol, done by the Mayo Clinic, also relied on receiving "alerts" that informed the provider with patient's gene sequence. ${ }^{[5]}$ Another study, the "1200 Patients Project," was done by Peter H. O’Donnell et al. Where a web-based "Genomic Prescribing System" (GPS) can provide a clinical interpretation of patient's genomic data for a given drug which can be accessible to the provider in a short summary. ${ }^{[4,6]}$ These are a few out of many efforts to analyze our current understanding of pharmacogenomics and its potential impact for the future.

Yet, a number of barriers prevent optimal utilization of pharmacogenomics into clinical practice. These include the availability of testing, the lack of evidence-based guidelines for prescribing, the ability to incorporate results into electronic medical records, and the education of health providers. ${ }^{[1]}$ According to the results of the RIGHT protocol, among primary care clinicians participated, $30 \%$ noted that pharmacogenomics were part of their formal training and education; $9 \%$ had discussed pharmacogenomics results with a patient; $52 \%$ did not plan to use or were unsure if they would use pharmacogenomics results in the future, and $7 \%$ expected to order or recommend a pharmacogenomics test for patients in the next 6 months. ${ }^{[1]}$

Physicians' current level of comfort to utilize pharmacogenomics, notably in the community setting, is a concern. At present, there is very little data examining correlations between physician comfort level to use pharmacogenomics and willingness to use it in clinical practice. In this study, a survey was conducted, incorporating a number of factors (age, number of articles read, conferences attended, and other variables as outline in the survey report) to assess reasons or behaviors that could influence clinicians to use or not use pharmacogenomics.

\section{Materials and Methods}

Our study consisted of a survey that was anonymously and voluntarily completed by physicians practicing in Kettering Health Network facilities. Physicians were requested by email to participate in a survey, containing 14 multiple choice questions regarding their understanding and beliefs regarding pharmacogenomics, as well as questions about specific professional details which were intended to explore how physician characteristics affected familiarity, and comfort and confidence in using pharmacogenomics data inpatient care. 1201 invitations were sent out, and 135 physicians participated in the study. Online platform SurveyMonkey was utilized for the development and distribution of online surveys as well as the extraction of survey responses and de-identification of respondents. All participants provided informed consent by clicking on a link embedded in the survey invitation email. The survey form is described in Appendix 1. This study is a quality improvement study and it is exempt from the institutional ethics review.

Initially, emails, including a hyperlink to the survey, were disseminated by administrative personnel in the Medical Staff office to physicians on both Kettering and Non-Kettering Physician Networks. On February 22, 2017, the emails were sent out using group emails without any intentional selection or exclusion process. To increase participation, followup email reminding physicians of the survey was sent out on March 3, 2017. The survey data were collected from February 22, 2017, to March 10, 2017. The data were then analyzed to assess for any significant relationship between participant variables and resulting survey data. Statistical Package for the Social Sciences (standard version 25) was used for statistical analysis. Initial data analyses consisted of calculating relevant Pearson correlation coefficients for relationships between and among continuous variables, and one-way analyses of variance for comparison of means between the two groups. A composite score of familiarity, comfort, and confidence with pharmacogenetics "scale scores" was summed after these three variables were found to be highly intercorrelated. The degree of correlation between physician variables and the scale scores was calculated using regression 
analysis with $P<0.05$ used to determine statistical significance. Analysis of variance (ANOVA) was used to determine the relationships between categorical variables and scale scores, and Bonferroni post hoc analysis was used to correct for possible false discovery.

\section{Results}

The survey was completed by 135 physicians. The sample size was adjusted to reflect the nonresponse rate in each section. With reference to the age distribution of the study participants, most participants were between 25 and 34 years of age; with the least falling within the range of 65 years and above [Figure 1]. The medical specialty with the most participants was general internal medicine. Although, seven participants failed to identify their specialty [Figure 2]. The familiarity, comfort, and confidence ratings with pharmacogenetics were

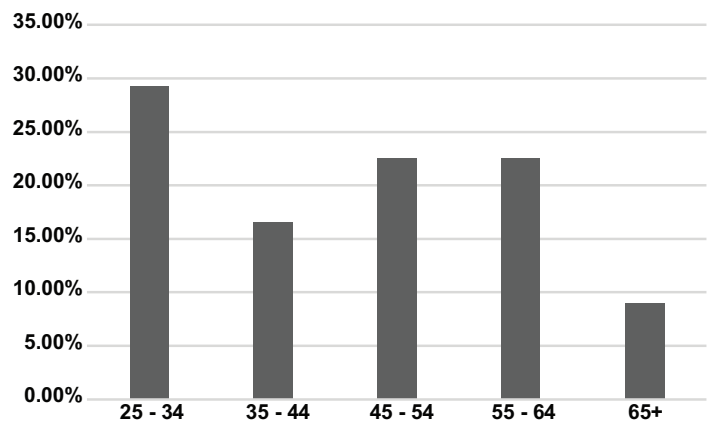

Figure 1: Age distribution of participants (Non-response rate $\mathbf{=} \mathbf{2}$ participants failed to indicate their age group) highly intercorrelated ( $r=0.81-0.87)$. Accordingly, we summed the three ratings to form a composite score of the three items (hereafter referred to as "scale scores"). Possible scores ranged from 5 to 15 , whereas actual scores ranged from 3 to 15 (Mean $=6.32, \mathrm{SD}=3.12$ ).

Gender distribution of participants based on survey response

\begin{tabular}{|l|c|}
$\begin{array}{l}\text { Gender } \\
\text { distribution }\end{array}$ & \multicolumn{1}{c|}{$\begin{array}{c}\text { Response rate } \\
\text { (Non-response rate=none) }\end{array}$} \\
\hline Female & $34.07 \%(46)$ \\
\hline Male & $65.93 \%(89)$ \\
\hline Total & $100 \%(135)$ \\
\hline
\end{tabular}

Age distribution of participants based on survey response

\begin{tabular}{|l|c|}
$\begin{array}{l}\text { Age } \\
\text { group }\end{array}$ & \multicolumn{1}{c|}{$\begin{array}{l}\text { Response rate } \\
\text { (Non-response rate=2; Adjusted } \mathbf{n = 1 3 3 )}\end{array}$} \\
\hline $25-34$ & $29.32 \%(39)$ \\
\hline $35-44$ & $16.54 \%(22)$ \\
\hline $45-54$ & $22.56 \%(30)$ \\
\hline $55-64$ & $22.56 \%(30)$ \\
\hline $65+$ & $9.02 \%(12)$ \\
\hline Total & $100 \%(133)$ \\
\hline
\end{tabular}

Scale scores were not statistically significant correlated with age $(r=0.12, P<0.17)$ or number of years in practice $(r=0.11, P<0.22)$ and were only weakly (inversely) correlated with number of hours spent in patient care each week

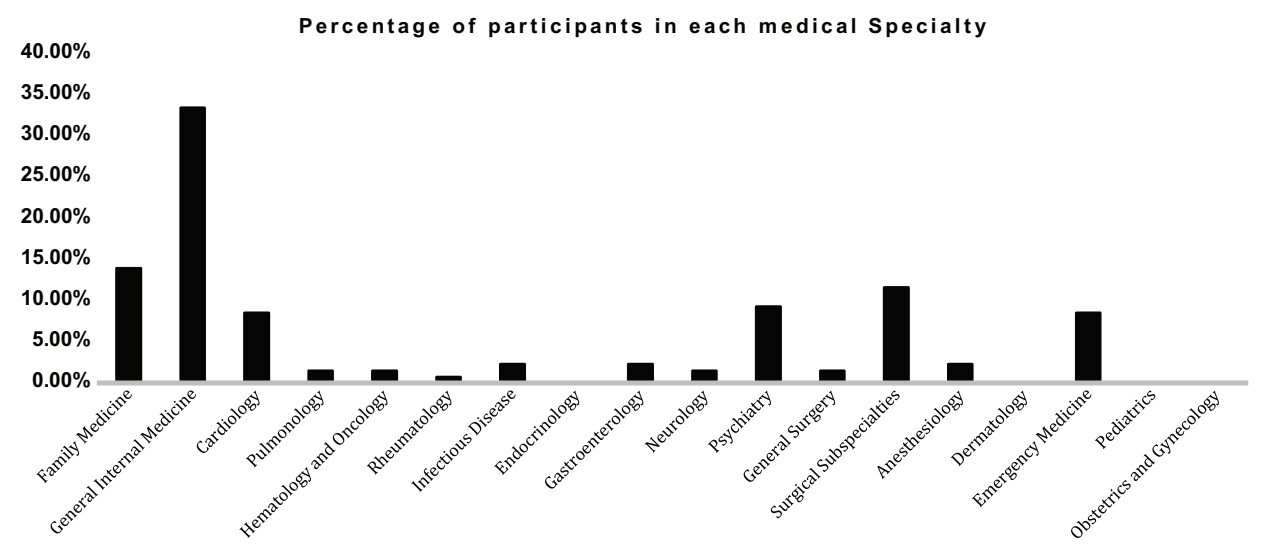

Figure 2: Medical specialty of participants (Non-response rate = 7; Adjusted sample size $=128$ ). No response was received for the following specialties: Obstetrics and gynecology, pediatrics, dermatology, and endocrinology) 


\section{Otchere, et al.: Use of pharmacogenomics data in clinical practice}

$(r=-0.17, P<0.05)$. Men (Mean =6.38, SD = 3.18) and women (Mean $=6.20, S D=3.03$ ) did not statistically significant differ in scale scores, $F(1,130)=0.11$, $P<0.75$. However, scale scores were statistically significant correlated with rated job satisfaction ( $r=0.27, P<0.002)$, the number of journal articles read per month $(r=0.28, P<0.002)$, and the number of medical conferences attended per year $(r=0.21$, $P<0.02)$. Scale scores were statistically significant greater among respondents who had encountered patients with drug metabolizing gene variants (Mean $=7.26, \mathrm{SD}=3.24$ ) compared to those who had not (Mean $=5.60, \mathrm{SD}=2.83), \mathrm{F}(1,130)=9.84$, $P<0.01$.

\section{Medical specialty of participants based on the survey response}

\begin{tabular}{|l|c|}
\hline Medical specialty & $\begin{array}{c}\text { Response rate } \\
\text { (Non-response rate=7; } \\
\text { Adjusted n=128) }\end{array}$ \\
\hline Family medicine & $14.06 \%(18)$ \\
\hline General internal medicine & $33.59 \%(43)$ \\
\hline Cardiology & $8.59 \%(11)$ \\
\hline Pulmonology & $1.56 \%(2)$ \\
\hline Hematology and oncology & $1.56 \%(2)$ \\
\hline Rheumatology & $0.78 \%(1)$ \\
\hline Infectious disease & $2.34 \%(3)$ \\
\hline Endocrinology & $0.00 \%(0)$ \\
\hline Gastroenterology & $2.34 \%(3)$ \\
\hline Neurology & $1.56 \%(2)$ \\
\hline Psychiatry & $9.38 \%(12)$ \\
\hline General surgery & $1.56 \%(2)$ \\
\hline Surgical subspecialties & $11.72 \%(15)$ \\
\hline Anesthesiology & $2.34 \%(3)$ \\
\hline Dermatology & $0.00 \%(0)$ \\
\hline Emergency medicine & $8.59 \%(11)$ \\
\hline Pediatrics & $0.00 \%(0)$ \\
\hline Obstetrics and gynecology & $0.00 \%(0)$ \\
\hline Total & $100 \%(128)$ \\
\hline
\end{tabular}

With regard to scale scores as a function of ever having received training in pharmacogenetics, those reporting such training (Mean $=8.12$, $\mathrm{SD}=3.11$ ) had statistically significantly higher scores compared to those who reported never having received such training (Mean $=4.95$,
$\mathrm{SD}=2.34), \mathrm{F}(1,130)=44.90, P<0.001$. Among those who had received some training, an overall ANOVA revealed that the three groups were statistically significant different, $F(2,54)=6.04$, $P<0.01$. Bonferroni post hoc comparisons revealed that scale scores among those who received training through continuing medical education (CME) (Mean $=9.18, \mathrm{SD}=2.93$ ) were greater than scale scores among those who received training during medical school (Mean $=6.25, S D=2.93$, $P<0.01$ ) but not statistically significant different from scale scores of those who received training in residency (Mean $=7.29, \mathrm{SD}=2.22, P<0.36$ ) . Scale scores of those who received training during medical school or residency were not statistically significant different $(P<1.00)$.

Because of overlap among the variables found to be statistically significant related to the scale scores, we performed a multiple regression analysis in which the predictor variables were the number of hours spent inpatient care each week, rated job satisfaction, having encountered patients with drug-metabolizing gene variants, the number of journal articles read per month, and the number of medical conferences attended per year were entered simultaneously. The overall regression equation was statistically significant, $F(6,124)=13.20, P<0.001$. However, only three predictor variables exhibited independent relationships with the scale scores: Having ever received training (Standardized Beta $=0.46$, $P<0.01$ ), having encountered patients with drug-metabolizing gene variants (Standardized Beta $=0.18, P<0.02)$, and rated job satisfaction (Standardized Beta $=0.66, P<0.03$ ).

\section{Other survey items and participant response rate}

1. How many years have you been in practice?

\begin{tabular}{|l|c|}
\hline $\begin{array}{l}\text { Number } \\
\text { of years }\end{array}$ & $\begin{array}{c}\text { Response rate (Non-response rate=1; } \\
\text { Adjusted } n=134)\end{array}$ \\
\hline $1-5$ & $34.33 \%(46)$ \\
\hline $6-10$ & $6.72 \%(9)$ \\
\hline $11-15$ & $10.45 \%(14)$ \\
\hline $16-20$ & $11.94 \%(16)$ \\
\hline $21-25$ & $8.96 \%(12)$ \\
\hline $26+$ & $27.61 \%(37)$ \\
\hline Total & $100 \%(134)$ \\
\hline
\end{tabular}




\section{Otchere, et al.: Use of pharmacogenomics data in clinical practice}

2. How many hours per week do you spend in direct patient care?

\begin{tabular}{|c|c|}
\hline $\begin{array}{l}\text { Hours per week } \\
\text { spent on direct } \\
\text { patient care }\end{array}$ & $\begin{array}{c}\text { Response rate } \\
\text { (Non-response rate }=2 \text {; } \\
\text { Adjusted } n=133 \text { ) }\end{array}$ \\
\hline $1-5$ & $3.01 \%(4)$ \\
\hline $6-10$ & $1.50 \%(2)$ \\
\hline $11-15$ & $3.01 \%(4)$ \\
\hline $16-20$ & $6.77 \%(9)$ \\
\hline $21-25$ & $7.52 \%(10)$ \\
\hline $26+$ & $78.20 \%(104)$ \\
\hline Total & $100 \%(133)$ \\
\hline
\end{tabular}

3. How many medical journals/articles do you read per month?

\begin{tabular}{|l|c|}
$\begin{array}{l}\text { Number of medical } \\
\text { journals/articles read } \\
\text { monthly }\end{array}$ & $\begin{array}{c}\text { Response rate } \\
\text { (Non-response rate=2; } \\
\text { Adjusted n=133) }\end{array}$ \\
\hline $0-2$ & $34.59 \%(46)$ \\
\hline $3-5$ & $30.83 \%(41)$ \\
\hline $6-8$ & $12.03 \%(16)$ \\
\hline $9-11$ & $7.52 \%(10)$ \\
\hline $12+$ & $15.04 \%(20)$ \\
\hline Total & $100 \%(133)$ \\
\hline
\end{tabular}

4. How many medical conferences/meetings do you attend per year?

\begin{tabular}{|l|c|}
$\begin{array}{l}\text { Number of } \\
\text { conferences/meetings } \\
\text { attended yearly }\end{array}$ & $\begin{array}{c}\text { Response rate } \\
\text { (Non-response rate=1; } \\
\text { Adjusted } n=134)\end{array}$ \\
\hline 0 & $17.91 \%(24)$ \\
\hline 1 & $33.58 \%(45)$ \\
\hline 2 & $26.87 \%(36)$ \\
\hline $3+$ & $21.64 \%(29)$ \\
\hline Total & $100 \%(134)$ \\
\hline
\end{tabular}

5. Rate your job satisfaction from 1 (least) to 5 (most).

\begin{tabular}{|l|c|}
$\begin{array}{l}\text { Level of job } \\
\text { satisfaction }\end{array}$ & $\begin{array}{r}\text { Response rate (Non-response } \\
\text { rate=3; Adjusted n=132) }\end{array}$ \\
\hline 1 & $3.03 \%(4)$ \\
\hline 2 & $3.79 \%(5)$ \\
\hline 3 & $19.70 \%(26)$ \\
\hline 4 & $47.73 \%(63)$ \\
\hline 5 & $25.76 \%(34)$ \\
\hline Total & $100 \%(132)$ \\
\hline
\end{tabular}

6. How familiar are you with pharmacogenomics? (1=least $5=$ most $)$

\begin{tabular}{|l|c|}
\multicolumn{1}{c}{$\begin{array}{c}\text { Level of } \\
\text { familiarity with } \\
\text { pharmacogenomics }\end{array}$} & $\begin{array}{c}\text { Response rate } \\
\text { (Non-response rate=1; } \\
\text { Adjusted n=134) }\end{array}$ \\
\hline 1 & $26.12 \%(35)$ \\
\hline 2 & $28.36 \%(38)$ \\
\hline 3 & $29.85 \%(40)$ \\
\hline 4 & $10.45 \%(14)$ \\
\hline 5 & $5.22 \%(7)$ \\
\hline Total & $100 \%(134)$ \\
\hline
\end{tabular}

7. How confident are you in your knowledge of pharmacogenomics? (1=least $5=$ most)

\begin{tabular}{|c|c|}
\hline $\begin{array}{l}\text { Confidence in level } \\
\text { of knowledge of } \\
\text { pharmacogenomics }\end{array}$ & $\begin{array}{c}\text { Response rate } \\
\text { (Non-response rate=3; } \\
\text { Adjusted } n=132 \text { ) }\end{array}$ \\
\hline 1 & $40.15 \%(53)$ \\
\hline 2 & $26.52 \%(35)$ \\
\hline 3 & $22.73 \%(30)$ \\
\hline 4 & $8.33 \%(11)$ \\
\hline 5 & $2.27 \%(3)$ \\
\hline Total & $100 \%(132)$ \\
\hline
\end{tabular}

8. How comfortable are you in using pharmacogenomics? (1=least 5=most)

\begin{tabular}{|c|c|}
\hline $\begin{array}{l}\text { Level of comfort } \\
\text { with regards to using } \\
\text { pharmacogenomics }\end{array}$ & $\begin{array}{c}\text { Response rate } \\
\text { (Non-response rate=1; } \\
\text { Adjusted } n=134 \text { ) }\end{array}$ \\
\hline 1 & $50.00 \%(67)$ \\
\hline 2 & $23.88 \%(32)$ \\
\hline 3 & $17.16 \%(23)$ \\
\hline 4 & $6.72 \%(9)$ \\
\hline 5 & $2.24 \%(3)$ \\
\hline Total & $100 \%(134)$ \\
\hline
\end{tabular}

9. Where did you receive your pharmacogenomics training?

\begin{tabular}{|l|c|}
\hline \multicolumn{1}{|l|}{ Site of training } & $\begin{array}{c}\text { Response rate (Non-response } \\
\text { rate=1; Adjusted } \mathbf{n = 1 3 4 )}\end{array}$ \\
\hline $\begin{array}{l}\text { Did not receive } \\
\text { training }\end{array}$ & $56.72 \%(76)$ \\
\hline Medical School & $11.94 \%(16)$ \\
\hline Residency training & $5.22 \%(7)$ \\
\hline $\begin{array}{l}\text { Continuing } \\
\text { medical education }\end{array}$ & $26.12 \%(35)$ \\
\hline Total & $100 \%(134)$ \\
\hline
\end{tabular}




\section{Otchere, et al.: Use of pharmacogenomics data in clinical practice}

10. Have you encountered any patients with drug metabolizing gene variants?

\begin{tabular}{|l|c|}
\hline \multicolumn{1}{|c|}{ Yes/No } & $\begin{array}{r}\text { Response rate (Non-response rate=1; } \\
\text { Adjusted } n=134)\end{array}$ \\
\hline Yes & $43.28 \%(58)$ \\
\hline No & $56.72 \%(76)$ \\
\hline Total & $100 \%(134)$ \\
\hline
\end{tabular}

11. How confident are you in your knowledge of pharmacogenomics and how it affects drug therapy.

\begin{tabular}{l|c|}
$\begin{array}{l}\text { Level of } \\
\text { confidence }\end{array}$ & $\begin{array}{r}\text { Response rate (Non-response } \\
\text { rate=1; Adjusted } n=134)\end{array}$ \\
\hline Not confident & $44.78 \%(60)$ \\
\hline Slightly confident & $26.87 \%(36)$ \\
\hline Somewhat confident & $20.15 \%(27)$ \\
\hline Quite confident & $8.21 \%(11)$ \\
\hline Very confident & $0.00 \%(0)$ \\
\hline Total & $100 \%(134)$ \\
\hline
\end{tabular}

\section{Discussion}

In 2015, St. Sauver et al. assessed the response of 159 primary care providers to pharmacogenomics clinical decision support alert in the electronic health records. Over half of the clinicians did not expect to use pharmacogenomics data in the future or did not see the utility of pharmacogenomics information in their future prescribing practices. This was in contrast to the patient's expectation that providers will tailor their drug therapy to fit the pharmacogenomics profile. ${ }^{[7]}$ Their group hypothesized that education in pharmacogenomics could potentially lead to increased satisfaction with pharmacogenomics alerts. ${ }^{[7]}$ It was not clear how half of the providers who were uncomfortable with pharmacogenomics and its alerts were different from their cohort. We had theorized that to increase participation of physicians in the implementation of pharmacogenomics in everyday practice it will be important to understand physician demographic and behavioral factors that will affect their interaction with pharmacogenomics in their clinical practice. This study has successfully characterized physician factors that will affect the familiarity, comfort, and confidence in using pharmacogenomics data in practice.

Using scaled score for familiarity, comfort, and confidence, we have shown that physicians' age does not predict their interaction with pharmacogenomics data $(r=0.12, P<0.17)$. The commonly held notion that older physicians may be slow to use innovation was not supported by our data, at least, not in the field of pharmacogenomics. Neither did the data suggest that physicians who spent more time in patient care were more likely to use pharmacodynamics data to affect therapy ( $r=-0.17, P<0.05)$.

Interestingly, a physician's self-rated job satisfaction correlated significantly to familiarity, confidence, and comfort in using pharmacogenomics information $(r=0.27, P<0.002)$. This finding has hitherto not been shown in the medical literature. The exact reason why job satisfaction correlates so strongly to confidence in using pharmacogenomics data is not entirely clear at this point. In fact, it is not yet known in the medical literature the relationship between job satisfaction and acceptance of new health innovation. There is, thus, opportunity for further research to clarify to interesting correlation. In our study, physicians who had some education in the field of pharmacogenomics were more likely to use pharmacogenomics data in clinical practice. The previous studies had alluded to this fact. ${ }^{[7,8]}$ What was not clear was the kind of education that predicted familiarity, confidence, and comfort in using pharmacogenomics. We have further characterized that CME, more than medical education, or residency training significantly predicts familiarity, confidence, or comfort in using pharmacogenomics data. This adds validity to the conclusion of Reed et al. that adult learning principles is an appropriate model to deliver pharmacogenomics education to health professionals. $^{[7]}$ In the United States, members of NIH's Pharmacogenomics Research Network have organized a Translational Pharmacogenomics Project that has been working on best practice guidelines that they seek to share with clinicians for proper integration of pharmacogenomics data into practice. ${ }^{[4,7-14]}$

This study adds new insight to our already expanding knowledge of ways to implement pharmacogenomics data in clinical practice. However, there are some limitations worth mentioning. This is a small singlecenter study; larger studies are needed to replicate these findings. Furthermore, this study was conducted in a community health network, whereas the majority of implementation studies have been conducted in large university hospitals. It is unclear whether physician characteristics found in our study can be extrapolated to physicians in university hospitals. ${ }^{[4,6,15-17]}$ Exclusion of non-physician primary 


\section{Otchere, et al.: Use of pharmacogenomics data in clinical practice}

care providers, such as nurse practitioners and physician assistants, is another limiting factor of this study.

\section{Conclusion}

In our study, physicians who had some education in the field of pharmacogenomics were more likely to use pharmacogenomics data in clinical practice. We have further characterized that $\mathrm{CME}$, more than medical education or residency training significantly predicts familiarity, confidence, or comfort in using pharmacogenomics data.

\section{Author Contributions}

All authors fulfilled the requirements to be listed as authors and approve of the submission of this manuscript for publication.

\section{Data Availability}

The authors declare that data supporting the findings of this study are available within the article.

\section{References}

1. St Sauver JL, Bielinski SJ, Olson JE, Bell EJ, Mc Gree ME, Jacobson DJ, et al. Integrating pharmacogenomics into clinical practice: Promise vs reality. Am J Med 2016;129:1093-99.

2. Wang L, McLeod HL, Weinshilboum RM. Genomics and drug response. N Engl J Med 2011;364:1144-53.

3. Kitzmiller JP, Groen DK, Phelps MA, Sadee W. Pharmacogenomic testing: Relevance in medical practice: Why drugs work in some patients but not in others. Cleve Clin J Med 2011;78:243-57.

4. O'Donnell PH, Danahey K, Jacobs M, Wadhwa NR, Yuen S, Bush A, et al. Adoption of a clinical pharmacogenomics implementation program during outpatient care--initial results of the University of Chicago "1, 200 Patients Project". Am J Med Genet C Semin Med Genet 2014;166c:68-75.

5. Weinshilboum RM, Wang L. Pharmacogenomics: Precision medicine and drug response. Mayo Clin Proc 2017;92:1711-22.

6. O'Donnell PH, Bush A, Spitz J, Danahey K, Saner D, Das S, et al. The 1200 patients project: Creating a new medical model system for clinical implementation of pharmacogenomics. Clin Pharmacol Ther 2012;92:446-9.

7. Bielinski SJ, Olson JE, Pathak J, Weinshilboum RM, Wang L, Lyke KJ, et al. Preemptive genotyping for personalized medicine: Design of the right drug, right dose, right time-using genomic data to individualize treatment protocol. Mayo Clin Proc 2014;89:25-33.

8. Vitek CR, Nicholson WT, Schultz C, Caraballo PJ. Evaluation of the use of clinical decision support and online resources for pharmacogenomics education. Pharmacogenomics 2015;16:1595-603.

9. O Gottesman, Scott $S A$, Ellis $S B$, Overby $C L$, Ludtke $A$, Hulot JS, et al. The CLIPMERGE PGX program: Clinical implementation of personalized medicine through electronic health records and genomics-pharmacogenomics. Clin Pharmacol Ther 2013;94:214-7.

10. Fernandez CA, Smith C, Yang W, Lorier R, Crews KR, Kornegay $\mathrm{N}$, et al. Concordance of DMET plus genotyping results with those of orthogonal genotyping methods. Clin Pharmacol Ther 2012;92:360-5.

11. Johnson JA, Burkley BM, Langaee TY, ClareSalzler MJ, Klein TE, Altman RB. Implementing personalized medicine: Development of a costeffective customized pharmacogenetics genotyping array. Clin Pharmacol Ther 2012;92:437-9.

12. Oetjens MT, Denny JC, Ritchie MD, Gillani NB, Richardson DM, Restrepo NA, et al. Assessment of a pharmacogenomic marker panel in a polypharmacy population identified from electronic medical records. Pharmacogenomics 2013;14:735-44.

13. Luzum JA, Pakyz RE, Elsey AR, Haidar CE, Peterson JF, Whirl-Carrillo $\mathrm{M}$, et al. The pharmacogenomics research network translational pharmacogenetics program: Overcoming the challenges of real-world implementation. Clin Pharmacol Ther 2013;94:207-10.

14. Pulley JM, Denny JC, Peterson JF, Bernard GR, Vnencak-Jones $\mathrm{CL}$, Ramirez $\mathrm{AH}$, et al. Operational implementation of prospective genotyping for personalized medicine: The design of the Vanderbilt PREDICT project. Clin Pharmacol Ther 2012;92:87-95.

15. Overby $\mathrm{CL}$, Devine EB, Abernethy N, McCune JS, Tarczy-Hornoch P. Making pharmacogenomicbased prescribing alerts more effective: A scenariobased pilot study with physicians. J Biomed Inform 2015;55:249-59.

16. Hinderer $M$, Boeker $M$, Wagner SA, Lablans $M$, Newe $S$, Hülsemann JL, et al. Integrating clinical decision support systems for pharmacogenomic testing into clinical routine a scoping review of designs of user-system interactions in recent system development. BMC Med Inform Decis Mak 2017;17:81.

17. Cutting $E$, Banchero $M$, Beitelshees AL, Cimino JJ, Del Fiol G, Gurses AP, et al. User-centered design of multi-gene sequencing panel reports for clinicians. J Biomed Inform 2016;63:1-10.

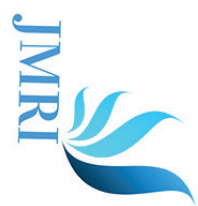

